\title{
The Drying and Preservation of Bacterial Gultures
}

\author{
By H. PROOM and LOIS M. HEMMONS \\ The Wellcome Research Laboratories, Beckenham, Kent
}

\begin{abstract}
SUMMARY : Working details are given for keeping as desiccates a collection of some 1500 strains of bacteria. The efficacy of drying, the various methods of freezing, and the effect of storage were tested by viable counts, using a spinning bottle modification of the roll-tube method. The survival rate of bacteria suspended in broth or other protective colloids, and subjected to freezing at $-78^{\circ}$, varied with the species from about $100 \%$ with the resistant Staphylococcus aureus to about $10 \%$ with the sensitive Neisseria gonorrhoeae, and from about 100 to $1.5 \%$ or less, respectively, when the organisms were suspended in saline. The percentage of organisms which survive the freeze-drying process was found to vary with the species, from $100 \%$ to less than $1.0 \%$ when the organisms were suspended in broth and from $100 \%$ to no survivors when the organisms were suspended in saline. The storage loss of dried cultures was found to be a function of the storage temperature; however, suitably dried cultures could be kept at room temperature for very long periods. By far the most important factor influencing loss on storage was the presence of traces of moisture, and to ensure optimal survival the cultures must be as dry as possible. It appears that even with adequately dried cultures the presence of oxygen is deleterious.

The survival rate of bacteria in a sample of dried culture after heating to $80^{\circ}$ for $1 \mathrm{hr}$, determined by plating a suspension of the heated sample in broth, provides a simple measure of the capacity of the particular batch of the dried culture to remain viable on storage at ordinary temperatures.
\end{abstract}

The drying of bacteria arouses most general interest as a solution of the utilitarian problem of avoiding the continuous subcultivation of strains and of maintaining them in any particular metabolic state. The essential requirements of a collection of dried cultures is that, with the routine employed, all strains should be viable as required, and not that particular batches of dried cultures should survive for very long periods. On this point, rather strangely in view of the spate of published methods for the preservation of bacteria, there is almost no information. We have maintained as desiccates a collection of some 1500 strains of different organisms, mainly pathogenic bacteria, for several years and have examined quantitatively the effect of freezing, drying, and storing dried bacteria under different conditions.

\section{METHODS}

Routine for drying bacterial cultures. The method used is that of Swift (1937) with minor modifications, and the routine we adopted is as follows. Most aerobic organisms are grown for 24-48 hr. on agar slopes of suitable media, and the growth emulsified with about $2 \mathrm{ml}$. of nutrient broth. The broth, containing $c .3 \mathrm{~g} . \mathrm{N} / \mathrm{l}$, is made by extracting fresh horse muscle with a papain digest of horse muscle containing $c .1 .5 \mathrm{~g} . \mathrm{N} / 1$.

Most anaerobic organisms are grown in $250 \mathrm{ml}$. amounts of nutrient broth, containing $0.01 \%$ thiolacetic acid, incubated for $24-48 \mathrm{hr}$., and the culture 
centrifuged. The broth emulsion, or broth deposit, is dispensed $(0.2 \mathrm{ml}$.) in small sterile plugged glass tubes about $0.7 \times 7.0 \mathrm{~cm}$. dimensions. The cottonwool plugs are cut off level with the top of the tubes. Twelve tubes of each culture are dried at a time, and the maximum number of tubes in one batch for drying is about one hundred. Powdered $\mathrm{CO}_{2}$ ice $(400 \mathrm{~g}$.$) is placed in$ a metal box which in turn is placed in a larger lagged wooden box. Powdered $\mathrm{CO}_{2}$ ice $(900 \mathrm{~g}$.) is added to $1 \mathrm{in}$. of glycerol in an $11 \mathrm{in}$. desiccator, and the tubes of culture are partially submerged in this mixture, when the temperature rapidly falls to about $-78^{\circ}$. A tripod supporting a dish of $\mathrm{P}_{2} \mathrm{O}_{5}$ is placed in the desiccator. The lid of the desiccator is connected to a Hyvac pump and the latter switched on and left running. The lid is pressed firmly on the desiccator which is then placed in the insulated box on top of the metal box containing the $400 \mathrm{~g}$. of $\mathrm{CO}_{2}$ ice. The following morning the tap of the desiccator is closed, the pump switched off, and the desiccator disconnected and placed on the bench for about $2 \mathrm{hr}$. to bring it up to room temperature. Dry nitrogen from a cylinder is run slowly into the desiccator, the tubes are removed and wiped free from glycerol; typed labels are then attached and the plugs pushed halfway down the tubes. This constitutes the primary drying; for the secondary drying the tubes are placed in a desiccator and redried in high vacuum at room temperature over $\mathrm{P}_{2} \mathrm{O}_{5}$ for 7 days. Dry nitrogen is then run into the desiccator, the tubes removed and sealed above the cotton-wool plugs. One tube from each culture is reconstituted for test.

Spinning bottle method of determining the viable count. The spinning apparatus consists of a $\frac{1}{50}$ h.p. electric motor mounted with the rotor shaft vertical; directly attached to the shaft is a brass cylinder. A $40 \mathrm{~W}$. electric lamp is placed in series to bring the speed to about 1000 r.p.m. The appropriate agar medium is dispensed in suitable amounts in sterile bottles of uniform external diameter plugged with cotton-wool. We have used bottles manufactured from standard bore glass tubing, of approximately $3.0 \mathrm{~cm}$. diameter and $4.5 \mathrm{~cm}$. height to the shoulder. The brass cylinder should be turned so that the bottles fit easily; a clearance up to a few millimetres does not matter. With bottles of this size a suitable amount of medium is $3.5 \mathrm{ml}$., and the concentration of agar (from Davis Gelatine (N.Z.) Ltd.) is increased slightly above normal, from 1.0 to $1.5 \%$, to ensure that the medium adheres well to the surface of the glass. When this melted $1.5 \%$ agar is spun in the machine the centrifugal force drives the medium up the sides of the bottle and it sets as a uniform layer from the bottom to the shoulder. Before inoculation the medium in the bottle is melted by steaming and the bottles are then placed in a water-bath at the lowest temperature necessary to prevent setting. We use a thermostatically controlled bath at $48^{\circ}$. The setting time of the $1.5 \%$ agar used varies from 40 to 90 sec. Experience has shown that it is advisable to have two spinners for one operator making the dilutions; the medium in the spinning bottle is then always set ready for the replacement of the next bottle. The culture to be counted is suitably diluted in broth and measured amounts added to the bottles which are then spun, incubated and the colonies counted.

Any accurate and convenient method of making dilutions is satisfactory. 
Since we desired to relate our results to the experience of the collection, the experiments were done on $\mathbf{0} \cdot \mathbf{2} \mathrm{ml}$. volumes of bacterial suspensions in small sterile cotton-wool plugged test-tubes of approximate dimensions $\mathbf{0 . 7} \times \mathbf{7 \cdot 0} \mathrm{cm}$. The final dilutions for counting were prepared by making up the volume in the tube to $1.0 \mathrm{ml}$. by adding 0.8 or $1.0 \mathrm{ml}$. of broth to the untreated or dried suspension respectively. Serial dilutions were then made to the appropriate extent by pipetting $0.5 \mathrm{ml}$. amounts into 100,50 or $10 \mathrm{ml}$. lots of broth contained in stoppered bottles. From the final dilution for counting $0 \cdot 3,0 \cdot 6$ and $0.9 \mathrm{ml}$. amounts, in duplicate, were pipetted into the bottles for spinning. Three separate series of dilutions were made from three tubes for each count; a typical result is shown in Table 1.

Table 1. Accuracy of viable counts on broth suspension of Escherichia coli

$0.2 \mathrm{ml}$. of broth suspension of $E$. coli strain $\mathrm{CN} 145$ filled into a series of glass tubes, diluted in broth for counting (dilution factor $1 \times 10^{8}$ )

\begin{tabular}{|c|c|c|c|c|}
\hline $\begin{array}{l}\text { Tube } \\
\text { tested }\end{array}$ & $\begin{array}{l}\text { Volume of suspension } \\
\text { added to separate } \\
\text { counting bottles } \\
\text { (in duplicate) (ml.) }\end{array}$ & $\begin{array}{l}\text { Colony counts } \\
\text { after spinning } \\
\text { and incubation }\end{array}$ & $\begin{array}{l}\text { Mean viable } \\
\text { counts for } \\
0.1 \mathrm{ml} .\end{array}$ & $\begin{array}{c}\text { Mean viable count of } \\
\text { original suspension } \\
\pm \text { standard error of } \\
\text { mean }\end{array}$ \\
\hline \multirow[t]{4}{*}{ A } & $0 \cdot 3$ & $\begin{array}{l}128 \\
151\end{array}$ & $46 \cdot 5$ & \multirow{4}{*}{$(44 \cdot 8 \pm 2 \cdot 28) \times 10^{8}$} \\
\hline & $0 \cdot 6$ & 272 & 48.2 & \\
\hline & & $\begin{array}{l}307 \\
395\end{array}$ & & \\
\hline & 0.9 & $\begin{array}{l}395 \\
319\end{array}$ & $40 \cdot 0$ & \\
\hline \multirow[t]{4}{*}{ B } & $0 \cdot 3$ & $\begin{array}{l}128 \\
130\end{array}$ & $43 \cdot 0$ & \multirow{4}{*}{$(42.9 \pm 0.338) \times 10^{8}$} \\
\hline & $0 \cdot 6$ & 265 & $43 \cdot 6$ & \\
\hline & & 259 & & \\
\hline & $0 \cdot 9$ & $\begin{array}{l}385 \\
375\end{array}$ & $42 \cdot 2$ & \\
\hline \multirow[t]{6}{*}{ C } & 0.3 & 143 & $47 \cdot 2$ & \multirow{6}{*}{$(45.2 \pm 0.937) \times 10^{8}$} \\
\hline & & 140 & & \\
\hline & $0 \cdot 6$ & 280 & 45.5 & \\
\hline & \multirow{3}{*}{0.9} & 266 & & \\
\hline & & 372 & $43 \cdot 0$ & \\
\hline & & 402 & & \\
\hline
\end{tabular}

\section{RESULTS}

Survival of dried cultures in large collection of bacterial strains

There are numerous isolated observations in the literature on the survival time of individual strains of certain species after particular dryings, but there is little information about the percentage of strains which remain viable after different intervals or about the periods after which species should be checked for viability and redried. Clearly this information is essential for the maintenance of a collection of bacterial cultures as desiccates. There are, however, a few published observations of this kind. Stillman (1941) reported that of $\mathbf{7 7 2}$ dried cultures of pneumococci $57 \%$ were viable after 3 years; Morton $\&$ Pulaski (1938) found that of sixty-seven cultures of various bacterial species 
fifty-two were viable and fifteen non-viable after 2-6 years in the dried state. Stamp (1947) reported that many pathogenic bacterial species could be preserved by drying at room temperature provided they were suspended in a nutrient gelatine ascorbic acid medium. A few species would not survive, but with others a high initial survival rate and low death-rate on storage was observed.

In order to ascertain the periods for which different species would remain viable, to ensure that all the cultures in the collection were viable, and to select suitable intervals for rechecking and redrying, the following routine was adopted. At least twelve tubes of a culture were dried at a time; and when five tubes remained the culture was redried, the five tubes from each drying being used to check the viability of cultures at selected intervals. Table 2 gives the results so far obtained, and is arranged so that the organisms are listed under their respective genera. Where more than twenty-five strains of one species are in the collection, or any particular species shows an abnormal susceptibility to drying, they are listed separately. It is clear that the majority of bacterial species will survive drying. In addition to the organisms listed, we have maintained successfully as desiccates strains of pleuropneumonia-like organisms, yeasts, dermatophytes, penicillia and other moulds; but leptospirae, bovine spermatozoa and two species of Protozoa were not viable after drying. There is considerable species variation in resistance to drying; for example, with 352 batches of dryings from 242 cultures of Gram-positive cocci every tube examined was viable, whereas with 431 dryings from 180 strains of Neisseria the first tube from eighty-eight batches of dryings failed to grow and in eighteen batches every tube was non-viable. The age of the batches examined extended up to 7 years.

With the possible exception of Clostridium perfringens the clostridia are very easily maintained in the dried state because of the extreme resistance of spores to damage by drying. With an old culture of Bacillus subtilis, which on microscopical examination appeared to consist entirely of spores, there was a $100 \%$ survival on drying. Clostridium perfringens does not spore readily in laboratory media (no spores were visible in stained preparations from our cultures), and the results suggest that the vegetative form of the genus is not as resistant to drying as the non-sporing Gram-positive acrobes. It is also evident that in order to maintain the collection satisfactorily there must be an established routine for checking and redrying strains which should be determined for the particular process used. The period between dryings would vary widely with the species.

\section{The effect of freezing on viability}

Table 3 shows the effect of freezing in $\mathrm{CO}_{2}$ ice (at $c .-78^{\circ}$ ) on the viability of organisms suspended in broth and in saline. The results are averages of several separate experiments. The organisms were grown on the appropriate solid media and washed off with saline or broth. The opacity of the suspension was adjusted to about $10^{9}$ organisms $/ \mathrm{ml}$. The percentage of organisms which survive freezing depends on the species and ranges from $100 \%$ for Staphy- 
lococcus aureus to $15 \%$ with the susceptible Neisseria gonorrhoeae. The majority of organisms appear to have a survival rate of about $50 \%$. Saline suspensions are usually less resistant than broth suspensions to freezing, the difference

\section{Table 2. Viability tests on stored batches of dried cultures}

Two tests were carried out. Test A: one tube from each batch was examined for viability. In the A columns are recorded the number of batches viable $(+)$ or non-viable $(-)$.

Test B : every tube in each batch which was negative in test $A$ was examined for viability. The figures in the $\mathrm{B}$ columns record the number of batches in which every tube was non-viable.

\begin{tabular}{|c|c|c|c|c|c|c|c|c|c|c|c|c|c|}
\hline \multirow{4}{*}{$\begin{array}{l}\text { Organism and no. of } \\
\text { strains examined }\end{array}$} & \multicolumn{12}{|c|}{ Period of storage (years) } & \multirow{4}{*}{$\begin{array}{c}\text { Routine } \\
\text { interval } \\
\text { before } \\
\text { redrying } \\
\text { (years) }\end{array}$} \\
\hline & \multicolumn{3}{|c|}{$5-4$} & \multicolumn{3}{|c|}{$4-3$} & \multicolumn{3}{|c|}{$3-2$} & \multicolumn{2}{|c|}{$2-1$} & & \\
\hline & \multicolumn{2}{|c|}{ A } & \multirow[b]{2}{*}{$\mathbf{B}$} & \multicolumn{2}{|c|}{$\mathbf{A}$} & \multirow[b]{2}{*}{ B } & \multicolumn{2}{|c|}{$\mathbf{A}$} & \multirow[b]{2}{*}{$\mathbf{B}$} & \multicolumn{2}{|c|}{$\mathbf{A}$} & & \\
\hline & + & - & & + & - & & + & - & & + & - & B & \\
\hline Alcaligenes spp. (5) & 2 & 0 & . & 5 & 0 & . & 2 & 0 & . & . & . & . & 3 \\
\hline Vibrio comma (3) & 4 & 2 & $\mathbf{2}$ & 2 & 2 & $\mathbf{0}$ & 6 & 2 & 2 & 5 & 2 & 0 & 1 \\
\hline$V$. foetus (2) & . & . & . & 5 & 0 & . & . & . & . & 2 & $\mathbf{0}$ & . & $\mathbf{3}$ \\
\hline Pseudomonas spp. (6) & 1 & $\mathbf{0}$ & . & 1 & 0 & . & 1 & $\mathbf{0}$ & . & 5 & $\mathbf{0}$ & . & $\mathbf{3}$ \\
\hline Staphylococcus spp. (73) & 2 & 0 & . & 25 & 0 & . & 38 & $\mathbf{0}$ & . & 14 & $\mathbf{0}$ & . & 5 \\
\hline Neisseria spp. (2) & 1 & 0 & . & . & • & . & $\mathbf{3}$ & $\mathbf{0}$ & . & . & • & . & 3 \\
\hline N. gonorrhoeae (79) & 43 & 13 & 3 & 40 & 25 & 9 & 20 & 9 & 2 & 58 & 18 & 2 & 1 \\
\hline N. intracellularis (36) & 41 & 3 & 0 & 27 & 11 & $\mathbf{2}$ & $\mathbf{2 4}$ & 7 & $\mathbf{0}$ & 30 & 8 & 1 & 2 \\
\hline Pasteurella spp. (25) & 4 & $\mathbf{0}$ & . & 11 & 1 & 1 & 14 & 1 & 1 & 2 & $\mathbf{0}$ & . & 3 \\
\hline Brucella spp. (20) & 5 & $\mathbf{0}$ & . & 12 & 1 & $\mathbf{0}$ & 8 & $\mathbf{0}$ & . & 1 & $\mathbf{0}$ & . & $\mathbf{5}$ \\
\hline Haemophilus spp. (15) & 3 & $\mathbf{2}$ & 0 & 10 & 2 & 1 & 20 & 1 & $\mathbf{0}$ & 15 & 1 & 0 & 2 \\
\hline H. pertussis (41) & 9 & 3 & 2 & 14 & 4 & 0 & 27 & 1 & $\mathbf{0}$ & 6 & $\mathbf{0}$ & 0 & 3 \\
\hline D. pneumoniae (41) & 10 & 0 & . & $\mathbf{2}$ & $\mathbf{0}$ & . & 15 & 0 & . & 27 & $\mathbf{0}$ & . & 5 \\
\hline Streptococcus spp. (128) & 21 & 0 & . & 41 & 0 & . & $\mathbf{5 4}$ & 0 & . & 39 & $\mathbf{0}$ & . & $\mathbf{5}$ \\
\hline Lactobacillus spp. (18) & . & . & . & 10 & 2 & 0 & 1 & $\mathbf{0}$ & . & 8 & $\mathbf{0}$ & . & $\mathbf{3}$ \\
\hline Esch. coli (113) & 72 & 6 & 0 & 17 & 1 & 0 & 51 & 1 & 0 & 103 & $\mathbf{0}$ & . & 3 \\
\hline Aerobacter spp. (8) & 2 & $\mathbf{0}$ & . & 2 & $\mathbf{0}$ & . & . & . & . & 6 & 0 & . & 3 \\
\hline Klebsiella spp. (2) & 2 & 0 & . & $\mathbf{2}$ & 0 & . & $\mathbf{l}$ & 0 & . & 1 & $\mathbf{0}$ & . & 3 \\
\hline Serratia spp. (4) & $\mathbf{3}$ & $\mathbf{0}$ & . & . & . & - & 4 & $\mathbf{0}$ & . & - & . & . & 3 \\
\hline Proteus spp. (3) & 2 & $\mathbf{0}$ & . & 1 & $\mathbf{0}$ & . & $\mathbf{2}$ & $\mathbf{0}$ & . & . & . & . & 3 \\
\hline Salmonella spp. (165) & 42 & 3 & 2 & 36 & 2 & 1 & 70 & 4 & $\mathbf{0}$ & 64 & $\mathbf{0}$ & . & $\mathbf{3}$ \\
\hline Shigella spp. (65) & 17 & 6 & 2 & 22 & 1 & 0 & 26 & 3 & 2 & 15 & 0 & . & 2 \\
\hline Listerella spp. (2) & 1 & $\mathbf{0}$ & . & . & . & . & . & . & . & $\mathbf{l}$ & 0 & . & 3 \\
\hline Bacillus spp. (20) & 2 & $\mathbf{0}$ & . & 8 & 0 & . & 3 & $\mathbf{0}$ & . & 10 & $\mathbf{0}$ & . & 5 \\
\hline Cl. novyi (22) & $\overline{1}$ & $\mathbf{0}$ & . & 4 & $\mathbf{0}$ & . & 14 & $\mathbf{0}$ & . & 6 & 0 & . & 5 \\
\hline Cl. perfringens (118) & . & . & . & 36 & $\mathbf{5}$ & $\mathbf{0}$ & 22 & 5 & $\mathbf{0}$ & 60 & 3 & $\mathbf{0}$ & $\mathbf{3}$ \\
\hline Cl. septicum (40) & . & . & . & 27 & $\mathbf{0}$ & . & 17 & $\mathbf{0}$ & . & 19 & $\mathbf{0}$ & . & 5 \\
\hline Clostridium spp. (32) & 1 & $\mathbf{0}$ & . & 14 & $\mathbf{0}$ & . & 7 & 0 & - & 21 & $\mathbf{0}$ & . & $\mathbf{5}$ \\
\hline C. diphtheriae (61) & 39 & 2 & $\mathbf{0}$ & 21 & 1 & $\mathbf{0}$ & 54 & $\mathbf{0}$ & - & $\mathbf{2}$ & $\mathbf{0}$ & - & 3 \\
\hline C. pyogenes (65) & 48 & 1 & $\mathbf{0}$ & 16 & $\mathbf{0}$ & . & 63 & $\mathbf{I}$ & . & 1 & $\mathbf{0}$ & . & 3 \\
\hline Corynebacterium spp. (24) & 4) 3 & $\mathbf{0}$ & . & 7 & $\mathbf{0}$ & . & 7 & $\mathbf{0}$ & - & 11 & $\mathbf{0}$ & . & 3 \\
\hline Mycobacterium spp. (25) & 3 & $\mathbf{0}$ & . & 17 & $\mathbf{5}$ & 0 & $\mathbf{5}$ & 0 & . & . & . & . & $\mathbf{3}$ \\
\hline Actinomyces spp. (5) & 1 & 0 & . & . & . & . & 3 & 0 & . & 1 & $\mathbf{0}$ & . & $\mathbf{3}$ \\
\hline E. rhusiopathiae (5) & 4 & $\mathbf{0}$ & . & - & . & - & 6 & 1 & $\mathbf{0}$ & 1 & $\mathbf{0}$ & . & 3 \\
\hline
\end{tabular}

being more marked with the organisms which are most susceptible. It is probable that the results for saline were weighted in favour of survival as the suspensions were not washed and therefore contained some soluble nutrients from the medium. The viability after freezing in other media, such as serum, $10 \%$ gelatine, or $\mathrm{M} / 60$ phosphate buffer was also determined; some of these 
media were as effective as broth, but none markedly superior. It appears that, provided protective substances are present, the initial loss on freezing is entirely related to the bacterial species. We have compared, with a number of organisms, the percentage survival after freezing to $-17^{\circ}$ and to $-78^{\circ}$ and have observed little significant difference in the numbers of organisms which survive.

Table 3. Viability of organisms after freezing in $\mathrm{CO}_{2}$ ice in broth and in saline

$0.2 \mathrm{ml}$. amounts of bacterial suspension frozen in small glass tubes; bottle method for viable counts.

\begin{tabular}{lcc} 
& \multicolumn{2}{c}{$\begin{array}{c}\text { Percentage survivals after } \\
\text { freezing to }-78^{\circ} \text { in }\end{array}$} \\
\cline { 2 - 3 }$\quad$ Organism & Saline & Broth \\
Staph. aureus & $109 \cdot 0^{*}$ & $100 \cdot 0$ \\
Esch. coli & $21 \cdot 5$ & $52 \cdot 0$ \\
Sh. dysenteriae & $25 \cdot 0$ & $96 \cdot 5$ \\
V. comma & $12 \cdot 0$ & $47 \cdot 0$ \\
N. intracellularis & $5 \cdot 0$ & $42 \cdot 0$ \\
N. gonorrhoeae & $1 \cdot 5$ & $15 \cdot 0$
\end{tabular}

The survival of organisms after drying in broth and saline at room temperature or from the frozen state

Table 4 summarizes the results of tests with six organisms of varying resistance to drying. Staphylococcus aureus represents the resistant class of Gram-positive cocci which remain viable in the dried state for many years. The survival rates may be as high as $100 \%$, and do not vary significantly whether the organism is dried in broth or saline, or at room temperature or from the frozen state. Escherichia coli and Shigella dysenteriae are intermediate in their resistance to drying, many cultures tending to die out after a few years as desiccates. The survival rate is still high, 20-60\%. On an average it is higher in cultures dried from the frozen state than in those dried at room temperature, although the difference is not marked. There is, however, a considerable diminution when saline is used as a suspending medium. Neisseria intracellularis, $N$. gonorrhoeae and Vibrio comma represent a class of organisms most sensitive to drying, the cultures beginning to die out after 2 years in the dried state. With these organisms the percentage survival is low, from 0.2 to $20 \%$, and drying the culture either at room temperature or suspended in saline kills either all or nearly all the cells.

Effect of age of culture. The age of the culture has some effect on its resistance to drying. Shigella dysenteriae was selected for test since it is intermediate in its resistance to drying. The organism was grown on agar and the total and viable counts made at intervals. The percentages of viable organisms at 5,7 , $9,12,24,48$ and $72 \mathrm{hr}$. were $11,18,11,15,6 \cdot 8,3 \cdot 2$ and $0 \cdot 28 \%$ respectively. The total counts were determined by opacity, using Brown's tubes and tables, and the viable counts by Miles \& Misra's method (1938). In one experiment 7 , 23 and $72 \mathrm{hr}$. cultures were dried, and in another $7,23 \mathrm{hr}$. and 6-day cultures. 
The first two periods were taken to represent approximately the beginning and end of the logarithmic growth stage and the last period the resting stage. Rather surprisingly the percentage survivals before and after drying were 20, 12.5 and 4.8 respectively in the first experiment and $24,12.4$ and 6.2 in the

Table 4. Viability of organisms suspended in broth or saline and dried at room temperature or from the frozen state after freezing in $\mathrm{CO}_{2}$ ice

\begin{tabular}{|c|c|c|c|}
\hline \multicolumn{4}{|c|}{ Viable counts by bottle method described in text. } \\
\hline Organisms & $\begin{array}{l}\text { Suspending } \\
\text { medium }\end{array}$ & $\begin{array}{l}\text { Temperature } \\
\text { of drying }\end{array}$ & $\begin{array}{l}\text { Survivals in different } \\
\text { experiments }(\%)\end{array}$ \\
\hline Staph. aureus & $\begin{array}{l}\text { Broth } \\
\text { Saline }\end{array}$ & $\begin{array}{l}\text { Room } \\
=78^{\circ} \\
\text { Room } \\
-78^{\circ}\end{array}$ & $\begin{array}{l}88 \cdot 6,51 \cdot 5,140 \cdot 0,60 \cdot 0,140 \cdot 0 \\
44 \cdot 1,42 \cdot 4,62 \cdot 1,127,73 \cdot 8 \\
34 \cdot 9,17 \cdot 2 \\
44 \cdot 1,27 \cdot 9\end{array}$ \\
\hline Esch. coli & $\begin{array}{l}\text { Broth } \\
\text { Saline }\end{array}$ & $\begin{array}{r}\text { Room } \\
-78^{\circ} \\
\text { Room } \\
-78^{\circ}\end{array}$ & $\begin{array}{l}43 \cdot 3,46 \cdot 2 \\
64 \cdot 6,25 \cdot 0,42 \cdot 4,34 \cdot 5,31 \cdot 9 \\
3 \cdot 57,1 \cdot 2 \\
58 \cdot 7,46\end{array}$ \\
\hline Sh. dysenteriae & $\begin{array}{l}\text { Broth } \\
\text { Saline }\end{array}$ & $\begin{array}{l}\text { Room } \\
-78^{\circ} \\
\text { Room } \\
-78^{\circ}\end{array}$ & $\begin{array}{l}33 \cdot 2,29 \cdot 1 \\
42 \cdot 3,10 \cdot 4,20 \cdot 7,28 \cdot 2,11 \cdot 4 \\
0 \cdot 74,0 \cdot 51 \\
2 \cdot 3,3 \cdot 2\end{array}$ \\
\hline N. intracellularis & $\begin{array}{l}\text { Broth } \\
\text { Saline }\end{array}$ & $\begin{array}{l}\text { lRoom } \\
-78^{\circ} \\
-78^{\circ}\end{array}$ & $\begin{array}{l}0 \cdot 69,0 \cdot 07,0 \cdot 15 \\
36 \cdot 2,19 \cdot 7,28 \cdot 8 \\
0 \cdot 003,0 \cdot 011,0 \cdot 03\end{array}$ \\
\hline V. comma & $\begin{array}{l}\text { Broth } \\
\text { Saline }\end{array}$ & $\begin{array}{l}\text { Room } \\
-78^{\circ} \\
-78^{\circ}\end{array}$ & $\begin{array}{l}5 \cdot 5,6 \cdot 2 \\
4 \cdot 7,9 \cdot 0,2 \cdot 6 \\
0 \cdot 1,0 \cdot 003,0 \cdot 01\end{array}$ \\
\hline N. gonorrhoeae & Saline & $\begin{array}{c}\text { Room } \\
-78^{\circ} \\
\text { Room } \\
-78^{\circ}\end{array}$ & $\begin{array}{l}\text { Nil, Nil, Nil } \\
0 \cdot 93,1 \cdot 33,0 \cdot 29 \\
\text { Nil, Nil, Nil } \\
\text { Nil, Nil, Nil }\end{array}$ \\
\hline
\end{tabular}

second. This suggests that young cultures are more resistant to drying, the sensitivity increasing somewhat with age. Similar results were obtained with Escherichia coli, but the differences were less marked.

\section{Storage loss}

The initial loss on drying a bacterial culture is related chiefly to the species. In the present state of knowledge it is unlikely that it will vary much for a given organism dried by the various methods so far described, always provided a protective substance is present and the organism is dried from the frozen state. But in addition to the initial loss, there is a considerable and progressive storage loss which is the significant factor in maintaining a collection of bacterial desiccates. Table 5 gives the storage losses with Esch. coli and Neisseria intracellularis at different temperatures for a period of 6 months. With these particular desiccates, which did not receive a secondary drying, the storage loss was considerable and showed a fairly steep temperature coefficient.

At this stage an attempt was made to develop a method of determining the 
probable storage loss without the long waiting period usually required. Accordingly counts were made on desiccates heated to 60,80 and $100^{\circ}$ for $1 \mathrm{hr}$. The decrease in viable count was considerable (Table 6). We obtained evidence that this loss runs parallel with the storage loss at lower temperatures. For example, the survival rates in a dried suspension of $N$. intracellularis after primary and secondary drying and storage for 1 month at room temperature

Table 5. Effect of temperature on storage loss

\begin{tabular}{lccccc}
\multicolumn{5}{c}{ Bottle method for viable counts. } \\
Percentage of surviving dried organisms \\
viable after
\end{tabular}

were 0.5 and $3 \cdot 2 \%$, and after 6 months less than 0.1 and $1.4 \%$. When these suspensions were heated immediately after completing the primary and secondary drying the survival rates after heating for $1 \mathrm{hr}$. at $60^{\circ}$ were $0 \cdot 13$ and $10.0 \%$ and after $1 \mathrm{hr}$. at $80^{\circ}$ were less than 0.02 and $0.1 \%$ with the primary and secondary dryings respectively. Similar results were obtained with a number of organisms, the differences between the two sets of figures varying considerably, according to the efficiency of the primary drying. It is likely that factors which lead to a high storage loss also result in a high loss on heating. This is a difficult point to prove decisively, and it is always possible that heating to high temperatures introduces factors which would not operate at room temperature. However, in practice it has proved a useful method of estimating probable storage loss.

The most obvious factor which might affect storage loss is the dryness of the resultant desiccate. With the routine method of drying and sealing it is probable

Table 6. Effect of heat on viability of dried cultures after primary and secondary drying

\begin{tabular}{|c|c|c|c|c|}
\hline \multirow[b]{2}{*}{ Organism } & \multirow[b]{2}{*}{ Drying } & \multicolumn{3}{|c|}{$\begin{array}{c}\text { Percentage of dried organisms surviving } \\
\text { after } 1 \mathrm{hr} \text {. at }\end{array}$} \\
\hline & & $60^{\circ}$ & $80^{\circ}$ & $100^{\circ}$ \\
\hline Esch. coli & $\begin{array}{l}\text { Primary } \\
\text { Secondary }\end{array}$ & $\begin{array}{c}0 \cdot 18 \\
56 \cdot 3\end{array}$ & $\begin{array}{l}0 \cdot 001 \\
9 \cdot 8\end{array}$ & $\begin{array}{l}0.0002 \\
0 \cdot 0008\end{array}$ \\
\hline Sh. dysenteriae & $\begin{array}{l}\text { Primary } \\
\text { Secondary }\end{array}$ & $\begin{array}{l}10 \cdot 6 \\
25 \cdot 0\end{array}$ & $\begin{array}{l}0.0031 \\
0.50\end{array}$ & $\begin{array}{l}0 \cdot 000009 \\
0 \cdot 00001\end{array}$ \\
\hline N. intracellularis & $\begin{array}{l}\text { Primary } \\
\text { Secondary }\end{array}$ & $\begin{array}{c}0 \cdot 11 \\
59 \cdot 2\end{array}$ & $\begin{array}{r}\text { Nil } \\
0 \cdot 79\end{array}$ & Nil \\
\hline N. gonorrhoeae & $\begin{array}{l}\text { Primary } \\
\text { Secondary }\end{array}$ & $\begin{array}{r}4 \cdot 4 \\
43 \cdot 3\end{array}$ & $\begin{array}{r}\text { Nil } \\
0 \cdot 14\end{array}$ & $\begin{array}{l}\text { Nil } \\
\text { Nil }\end{array}$ \\
\hline
\end{tabular}


that a slight and varying amount of moisture remains after the initial drying. It is apparent from Table 6 that the more effectively dried desiccates are more resistant to heat and would probably survive for a longer period. We have observed in the collection that where a particular desiccate appears to be damp the culture is usually non-viable.

Table 7 shows the survival rate on drying and heating to 60 and $80^{\circ}$ for a variety of non-sporing pathogens. Counts were made by Miles \& Misra's (1938) method. The organisms are listed in the order of survival rate after secondary drying. The organisms most resistant to drying are most resistant to $80^{\circ}$ for $1 \mathrm{hr}$., and would presumably survive longer in the dried state. The results correlate well with our general experience with the collection; that is, the survival rate after drying indicates the ability of a strain to survive in the dried state. The survival rate after heating to $80^{\circ}$ also indicates, in addition, the probable storage life of that particular drying.

Table 7. Effect of heat on dried cultures of bacteria

\begin{tabular}{|c|c|c|c|c|}
\hline \multirow[b]{2}{*}{ Species } & \multirow{2}{*}{$\begin{array}{c}\text { Organisms } \\
\text { surviving } \\
\text { drying }(\%)\end{array}$} & \multicolumn{2}{|c|}{$\begin{array}{c}\text { Dried organisms } \\
\text { viable after } 1 \mathrm{hr} .(\%)\end{array}$} & \multirow{2}{*}{$\begin{array}{l}\text { Survival in the } \\
\text { collection }\end{array}$} \\
\hline & & at $60^{\circ}$ & at $80^{\circ}$ & \\
\hline Str. pyogenes & $120 \cdot 0^{*}$ & $120 \cdot 0$ & $68 \cdot 0$ & Good \\
\hline Br. abortus & $100 \cdot 0$ & $82 \cdot 0$ & $\mathbf{2 9} \cdot \mathbf{0}$ & Good \\
\hline Ery. rhusiopathiae & $67 \cdot 0$ & $\mathbf{8 2 \cdot 0}$ & $70 \cdot 0$ & Good \\
\hline H. pertussis & $49 \cdot 0$ & $60 \cdot 0$ & $3 \cdot 0$ & Intermediate \\
\hline C. diphtheriae & $40 \cdot 0$ & $62 \cdot 0$ & $25 \cdot 0$ & Good \\
\hline Salmonella typhosa & $37 \cdot 0$ & $22 \cdot 0$ & $7 \cdot 0$ & Intermediate \\
\hline Esch. coli & $30 \cdot 0$ & $60 \cdot 0$ & $5 \cdot 3$ & Intermediate \\
\hline Sh. dysenteriae & $10 \cdot 0$ & $25 \cdot 0$ & 0.5 & Poor \\
\hline N. intracellularis & $7 \cdot 6$ & $10 \cdot 0$ & $0 \cdot 14$ & Poor \\
\hline H. influenzae & 6.5 & $50 \cdot 0$ & $0 \cdot 4$ & Poor \\
\hline Past. boviseptica & $6 \cdot 0$ & $92 \cdot 0$ & $2 \cdot 6$ & Intermediate \\
\hline N. gonorrhoeae & 0.5 & $35 \cdot 0$ & $0 \cdot 14$ & Poor \\
\hline
\end{tabular}

A few tests were made of the effect of gases on storage loss. Cultures after primary drying were redried on a glass manifold for 4 days over $\mathrm{P}_{2} \mathrm{O}_{5}$ under high vacuum. The manifold was so arranged that the tubes could be sealed either in vacuo or containing selected gases. Cultures sealed in vacuo, dry nitrogen, oxygen, air and by the routine process were compared. In one experiment with $N$. intracellularis the survival rates after $1 \mathrm{hr}$. at $80^{\circ}$ of cultures sealed in oxygen, air, nitrogen, in vacuo and by the routine process were $1 \cdot 4,0 \cdot 9,9 \cdot 0,9 \cdot 4$ and $0 \cdot 7 \%$ respectively. The nitrogen was dry and the oxygen probably dry, and the air was let in from the atmosphere. These results suggest that the storage loss with air, oxygen or the routine sealing process is about ten times as great as when the tubes are sealed in nitrogen or vacuum without being exposed to the atmosphere before sealing. It is likely that the loss with oxygen was due to the gas, although from the tests so far made it is not possible to exclude the possibility that it was due in part to traces of moisture. 


\section{DISCUSSION}

Our experience with a working collection of 1500-2000 strains of bacteria has shown that it is practical, economical and efficient to keep them as desiccates. The main interest of many of these strains has been their specific pathogenic, toxigenic or antigenic properties, and it has been necessary not only to maintain pure cultures but cultures retaining these characteristics quantitatively. A very large number of strains and species in our collection have been used repeatedly for virulence tests, toxin production, the preparation of diagnostic sera and suspensions, sensitivity to chemotherapeutic agents, etc., and so far as can be ascertained they have been found to maintain quantitatively, in the dried state, the properties of the original cultures. It is possible that this may not always be the case, but we have not yet observed any exceptions. We have noticed that dried cultures have an unusually long lag phase when subcultivated, and are best recovered on a medium of optimal growth-promoting properties. We have observed that motility is not evident immediately on reconstituting a dried motile bacillus, but is observable within half an hour, before any extensive multiplication could have occurred.

The technical staff necessary for maintaining the collection is relatively small. One senior technician and two assistants have been able to perform the drying and checking of cultures, the standard bacteriological examination of the strains and the issue of some $\mathbf{3 0 0 0}$ cultures a year. The alternative methods of keeping the strains with the consequent subculturing, repetition of animal passage, selection of colonies and so on would be impracticable.

In keeping a collection of bacterial desiccates the methods employed should ensure a high percentage survival on drying and low storage loss. The routine should be simple enough for a responsible junior technician, and should ensure that the cultures are kept pure during the process of drying and recovery. For this reason we dislike the process of snap-freezing, which cannot be done through cotton-wool plugs, and the drying of drops of culture on cellophan squares. Both of these processes add to the risk of contamination; this becomes more than a theoretical point when large numbers of cultures are being dried. We have done sufficient experiments with snap-freezing, Rayner's method (1943) and Stamp's method (1947) to be satisfied that these methods do not give significantly higher survival rates than our routine process. We have been unable to relate the low storage loss reported by Stamp (1947) to the medium he employs, and believe this to be due to the efficiency of the secondary drying.

Providing that certain precautions be taken, such as using a protective colloid and drying from the frozen state, the percentage of organisms surviving initially is dependent only on the strain. The nature of the protective colloid, the age of the culture and the temperature at which the organisms are frozen and from which they are dried, and the numerous techniques of freeze-drying described in the literature, may make some difference to the initial survival rate, but in our experience these differences have been small and not very important. Our experiments throw some light on the cause of death by freezing for which two main reasons have been advanced (cf. Rahn, 1945). 
These are: damage to the cell by intracellular or extracellular ice formation, and protein denaturation due to changes in the physical state. We have observed that only two factors influence the survival rate after freezing: the species and the nature of the suspending medium. Since protective colloids, such as gelatine, which cannot pass through the cell wall, materially decrease the loss on freezing, it seems probable that extracellular factors, presumably ice formation, are responsible for death. We favour the hypothesis that the cell wall is punctured by extracellular ice crystals. Species differences would then be differences in the strength of the cell wall; in this connexion it may be more than a coincidence that organisms such as Neisseria intracellularis, $N$. gonorrhoeae and Vibrio comma, which are particularly susceptible to freezing, often show many degenerative forms on microscopical examination. The function of the protective colloid would then be to protect the organism against damage by ice crystals.

We have found two factors of paramount importance in avoiding a high storage loss. In the first place the cultures must be as dry as possible; secondly, they should be sealed in an atmosphere of dry nitrogen or in vacuo. It is possible that both the presence of oxygen and of traces of moisture are responsible for the higher storage loss when the tubes are taken out of the desiccator before sealing. Cultures that are not completely dry will not keep well in any case, but it is probable that even with completely dry cultures the storage loss would be less in vacuo or in nitrogen than in oxygen or air. The temperature of storage also has some effect, and dried cultures will survive longer in the cold room than at room temperature. One difficulty of sealing in vacuo is that when the tubes are opened the inrush of air is likely to contaminate the culture, or, when the tubes are sealed over a cotton-wool plug, to push the plug down to the bottom of the tube when it is opened; consequently we prefer sealing in dry nitrogen. The difficulty with nitrogen is that one cannot easily test for pinholes which may be present after the sealing process, as can be done when sealing in vacuo, by a high-tension vacuum tester. We have attempted to overcome this difficulty by including a few granules of dried silica gel over the cotton-wool plug. This acts as a secondary desiccant and in the presence of a leak absorbs moisture from the atmosphere, changing colour and acting as an indicator of the faulty sealed tubes. In practice the imperfectly sealed tube has been rare.

One of the difficulties in keeping a collection of desiccates is to know how any particular drying will survive, and a routine test to ascertain this would be of extreme value. We have devised such a test, which in our limited experience is promising. The test consists in heating one tube of the batch in a water-bath for $1 \mathrm{hr}$. at $80^{\circ}$ and subcultivating. The number of organisms dried by the routine process is of the order of $10^{\circ}$. Should the drying be satisfactory, then after heating the number of organisms which survive should be of the order of $10^{7}$ or more in the resistant and intermediate groups, and $10^{4}$ in the susceptible group. If the drying is unsatisfactory the survivals are from 100 to more than 1000 times less (see Tables 6 and 7). Consequently if about $2 \mathrm{ml}$. of broth are added to the heated tube and 1 drop (about $0.05 \mathrm{ml}$.) is 
placed on an agar medium plate, then with a successful drying there should be confluent growth with the resistant and intermediate groups and a fairly large number of colonies with the susceptible group. With an unsuccessful drying there would be isolated colonies with the first two groups and no growth with the last.

Our thanks are due to Mr E. Harris for technical assistance in maintaining the bacterial collection.

\section{REFERENCES}

Kyes, P. \& Potter, T. S. (1939). Resistance of avian tubercle bacilli to low temperature with especial reference to multiple changes in temperature. J. infect. Dis. 64, 123.

Miles, A. A. \& Misra, S. S. (1938). Estimation of bactericidal power of blood. J. Hyg., Camb., 38, 732.

Morton, H. E. \& Pulaski, E. J. (1938). Preservation of bacterial cultures. J. Bact. $35,163$.

Rahn, O. (1945). Physical methods of sterilization of micro-organisms. Bact. Rev. $9,1$.

Rayner, A. G. (1943). Simple method for the preservation of cultures and sera by drying. J. Path. Bact. 55, 373.

StAMP, LoRd (1947). The preservation of bacteria by drying. J. gen. Microbiol. $1,251$.

StILlman, E. G. (1941). The preservation of pneumococcus by freezing and drying. J. Bact. 42, 689.

SwiFT, H. F. (1937). A simple method for preserving bacterial cultures by freezing and drying. J. Bact. 33, 411. 